\title{
The Leptin to Adiponectin Ratio is a Marker of the Number of Metabolic Syndrome Criteria in French Adults
}

A Gauthier ${ }^{1}$, S Dubois ${ }^{1}$, S Bertrais ${ }^{2}$, Y Gallois ${ }^{3}$, C Aube ${ }^{4}$, F Gagnadoux ${ }^{5}$, P Cales ${ }^{2}$, V Rohmer ${ }^{1}$, G Leftheriotis ${ }^{6}$, PH Ducluzeau ${ }^{1 *}$

${ }^{1}$ Département de diabétologie-nutrition, CHU Angers, 4 rue Larrey, Angers, F-49033 France

'Laboratoire HIFIH, UPRES 3859, IFR 132, Université d'Angers, F-49033 France

${ }^{3}$ Département de biologie, CHU Angers, 4 rue Larrey, Angers, F-49033 France

${ }^{4}$ Département de radiologie, CHU Angers, 4 rue Larrey, Angers, F-49033 France

${ }^{5}$ Département de pneumologie, CHU Angers, 4 rue Larrey, Angers, F-49033 France

${ }^{6}$ Département d'exploration fonctionnelle vasculaire, CHU Angers, 4 rue Larrey, Angers, F-49033 France

\section{Abstract}

Aim: Visceral distribution of adipose tissue (AT) is one of the key components of Metabolic Syndrome (MetS). Plasma concentrations of leptin and adiponectin are closely linked to AT distribution. Pulse wave velocity (PWV), a marker of arterial stiffness, is linked to metabolic syndrome and cardiovascular risk. The purpose of this study is to describe the extent of the usefulness of the Leptin/Adiponectin (L/A) ratio as a marker of MetS.

Methods: Leptin and adiponectin concentrations, magnetic resonance image-based of visceral and subcutaneous fat measurements, and carotid PWV were analyzed in the subjects of a French prospective cohort composed of 97 subjects not presenting metabolic syndrome (MetS-), 122 patients with metabolic syndrome (MetS+) without diabetes, and 94 type 2 diabetics (T2D) with MetS.

Results: After adjustment for gender and age, leptinemia was found to be higher in MetS+ patients than in T2D patients. Adiponectinemia alone was not discriminated. There was a statistically significant difference in the L/A ratio between MetS- patients and the other groups. For the whole population, there is a positive correlation between the L/A and waist circumference, waist-to-hip ratio, visceral fat $(r=0.53)$, triglyceride concentrations, fasting glucose concentrations, insulinemia, systolic and diastolic blood pressure, and number of MetS criteria ( $r=0.39)$. The L/A ratio is also significantly correlated with carotid artery stiffness.

Conclusion: This study demonstrates the potential usefulness of the L/A ratio as a marker, independent of age and gender, of a subject's metabolic risk. The L/A Ratio is also a reliable marker for arterial stiffness.

Keywords: Adipokines; Metabolic syndrome; Arterial stiffness

\section{Introduction}

Metabolic syndrome is defined as the association of several criteria, including android fat distribution, dyslipidemia, high blood pressure, and diabetes or impaired glucose tolerance. There are several accepted definitions, which, while they vary little in their criteria, may present differing threshold concentrations of abdominal perimeter, depending on the ethnic groups involved. One of the most commonly cited is the International Diabetes Federation (IDF) definition [1] used in this study. The key component of metabolic syndrome is insulin resistance, closely linked to visceral obesity, hepatic steatosis and type 2 diabetes. It is characterized by impairment of the effect of insulin on target tissues, mainly muscle, fat and liver, linked to storage in those tissues of excessive amounts of triglycerides, due to reduced oxidation of fatty acids. Prevalence of metabolic syndrome is rising throughout the world, and in 2008 it affected between $9 \%$ and $21 \%$ of the population, depending on the author [2]. In 2005, about $40 \%$ of Americans over 20 years of age were said to be affected when IDF criteria were used [3]. In France, recent epidemiological data from a French population of 1608 men and women aged between 18 and 74 showed an IDF-defined prevalence of metabolic syndrome of $14 \%$ [4]. Metabolic syndrome is linked to android distribution of adipose tissue and is associated with cardiovascular risk [5].

Interest in metabolic syndrome has risen in parallel with the discovery of adipokines such as leptin and adiponectin. These molecules, secreted primarily by adipose tissue, may be linked to the presence of metabolic syndrome by modulating energy consumption, thermogenesis, food intake and metabolic homeostasis and thus, may play a role in the development of insulin resistance, hepatic steatosis, and type 2 diabetes [6]. Serum leptin concentrations have been found positively associated with cardiovascular risk factors, hypertension, and dyslipidemia [7]. The WOSCOPS study found a positive correlation between leptinemia and coronary artery disease, with a risk level of 1.7 for the quintile showing the highest leptin concentrations [8]. The incidence of stroke is positively associated with plasma leptin concentrations, regardless of other cardiovascular risk factors, after Body Mass Index (BMI) adjustment [9]. Leptin is therefore linked to cardiovascular risk factors and the appearance of cardiovascular events. Adiponectin allows for a reduction in triglyceride storage in adipose and muscular tissue by promoting fatty acids oxidation within the cells. It acts as an insulin sensitizer by reducing hepatic gluconeogenesis [10]. Plasma concentrations of adiponectin, ranging between 1.9 and $17 \mathrm{mg} / \mathrm{ml}$ in healthy subjects, vary with gender, age, ethnic group, and body weight. Concentrations are highest among thin people and decrease with android weight distribution [11]. Adiponectin is lower in the non-diabetic obese and in insulin-resistant patients, regardless of fat mass [12,13]. Low concentrations of adiponectin are associated with the presence of cardiovascular risk factors, in particular essential hypertension and hypertriglyceridemia [14,15]. Moreover, Kojima et

*Corresponding author: PH Ducluzeau, Département de diabétologie-nutrition, CHU Angers, 4 rue Larrey, Angers, F-49033 France, Tel: +33 2413544 97; Fax: +33 2413559 00; E-mail: phducluzeau@chu-angers.fr

Received October 25, 2011; Accepted December 15, 2011; Published December 31, 2011

Citation: Gauthier A, Dubois S, Bertrais S, Gallois Y, Aube C, et al. (2012) The Leptin to Adiponectin Ratio is a Marker of the Number of Metabolic Syndrome Criteria in French Adults. J Metabolic Synd 1:101. doi:10.4172/2167-0943.1000101

Copyright: (C) 2012 Gauthier A, et al. This is an open-access article distributed under the terms of the Creative Commons Attribution License, which permits unrestricted use, distribution, and reproduction in any medium, provided the original author and source are credited. 
al. demonstrated that there is a negative association between intima media thickness and adiponectin concentrations [16].

Leptin and adiponectin may therefore be good diagnostic markers as well as, possibly, good predictors of metabolic syndrome and type 2 diabetes [17]. Recent studies, however, have demonstrated a stronger association between the leptin/adiponectin (L/A) ratio or the inverse ratio $(\mathrm{A} / \mathrm{L})$ and metabolic syndrome on the one hand, than the association between leptin or adiponectin alone and MetS on the other [18]. However, some studies have made the opposite findings. Mojiminiyi's team shows that adiponectin is a better marker of metabolic syndrome in type 2 diabetics than the L/A ratio [19]. Intima-media thickness may be independently linked to the L/A ratio in diabetic and non-diabetic patients [20,21]. A simple marker of arterial stiffness is Pulse Wave Velocity (PWV). It has been shown that aortic PWV is positively correlated with the Framingham score, and therefore with overall cardiovascular risk, in various populations, with or without atherosclerosis [22]. More recently, Achimastos's team demonstrated that a high PWV is an independent determinant of the presence of metabolic syndrome [23].

Therefore, conflicting data exist concerning the role of adiponectin and leptin, and their ratio, with the presence of metabolic syndrome and the number of criteria of the syndrome. Studies have often been undertaken on specific populations: healthy, type 2 diabetes. In this study, we investigated for the first time in a French Caucasian adult population the relationships of L/A ratio with the number of criteria of metabolic syndrome based on the IDF definition, adipose tissue distribution assessed by MRI and vascular stiffness assessed by carotid pulse wave velocity.

\section{Materials and Methods}

\section{Subjects}

A total of 313 French adult subjects, 242 men and 71 women, were constitutive of the Numevox cohort. The objective of this cohort (registered on clinicaltrials.gov under the number NCT00997165) is to describe the impact of the distribution of fat on vascular and metabolic evolution in patients initially thought to be at increased cardiovascular risk by their doctor. Patients included were initially sent by pneumologists, hepatologists and diabetologists for metabolic exploration in the department of nutrition of the Angers university hospital, in France. The study was approved by the institutional ethics committees, and for each patient, oral and written consent was obtained in a process validated by the Ethical Research Committee of Angers university hospital. Patients included in the study cohort were aged between 30 and 75 years and the following exclusion criteria were applied : BMI $>40 \mathrm{~kg} / \mathrm{m}^{2}$; poorly controlled diabetes with $\mathrm{HbAlc}>$ 9\%; insulin-treated diabetes; uncontrolled severe arterial hypertension (>180/120 mmHg); severe hypertriglyceridemia (TG $>10 \mathrm{~g} / \mathrm{l})$; severe renal failure (creatinine clearance $<30 \mathrm{ml} / \mathrm{min}$ ) or any contraindication to MRI.

\section{Diagnostic classification}

During hospitalization, a thorough clinical examination was carried out, including weight, height, waist, and hip measurements. The Waistto-Hip Ratio (WHR) and BMI were calculated. A 12-lead rest ECG was done, as well as a 15-minute brachial blood pressure test using an automatic blood pressure cuff. Next, patients were classified into groups according to the presence or absence of metabolic syndrome or type 2 diabetes (MetS+, MetS-, and T2D). The definition of metabolic syndrome used here is IDF 2005. That definition includes the presence of central obesity, along with at least 2 of the following criteria: triglyceride concentration greater than $1.50 \mathrm{~g} / \mathrm{l}$; HDL cholesterol concentrations lower than $0.40 \mathrm{~g} / \mathrm{L}$ in men or 0.50 in women or the taking of hypolipemic medication; systolic blood pressure greater than $130 \mathrm{mmHg}$ or diastolic pressure greater than $85 \mathrm{mmHg}$ or anti hypertension treatment; fasting glucose concentrations greater than 1 $\mathrm{g} / \mathrm{l}(5.6 \mathrm{mmol} / \mathrm{l})$ or a known type 2 diabetes. Central obesity is defined as waist circumference exceeding $94 \mathrm{~cm}$ in men and $80 \mathrm{~cm}$ in women. For each patient, a ten-year risk of coronary heart disease was estimated using the Framingham-Laurier equation.

\section{Blood tests}

Samples were taken during fasting, before any medications had been taken. Leptin concentration was measured using an enzymelinked immunosorbent assay (Millipore, USA). Adiponectin was measured using an enzyme-linked immunosorbent assay kit with intra- and inter-assay coefficients of variation of $7.25 \%$ and $6.32 \%$ respectively (Millipore, USA). Each patient's blood sample was tested for blood electrolyte level, fasting glucose, insulinemia, HbA1c, creatininemia, as well as liver function including ASAT, ALAT, gGT, ferritiniemia, and hyaluronic acid. The Lipid Profile included total cholesterol concentrations, HDL-C, LDL-C, trigylceridemia, ApoB, ApoA1, and Lpa. Protein electrophoresis, NFS, CRPus, fibrinogen, TP, ProBNP, and microalbuminuria tests were also carried out. Insulin resistance was evaluated using the HOMA-IR index (Homeostasis Model Assessment Insulin Resistance $=($ fasting insulin concentration $(\mu \mathrm{U} / \mathrm{mL}) \times$ fasting glucose concentration $(\mathrm{mmol} / \mathrm{l})) / 22.5)$.

\section{Imaging}

An abdominal MRI was performed on 161 patients as a mean to assess intra and retro peritoneal visceral adipose tissue (VAT) and subcutaneous adipose tissue (SAT), in square centimeters. The imaging was carried out on a 1.5T MRI (GEMS Milwaukee, Il) with a phasedarray surface coil. Area of visceral and subcutaneous fat were calculated on T1 opposite phase gradient echo sequence, using validated software developed in cooperation with the Radiology Department of the University Hospital of Angers (24). We also calculated the percentage of visceral fat in abdominal fat deposits (VAT in $\%=\mathrm{VAT} /$ $(\mathrm{VAT}+\mathrm{SAT}))$. Each patient also received a supra-aortic trunk Doppler Ultrasound with measurement of Intima-Media Thickness (IMT) and minimum carotid diameter. The IMT measurement, in millimeters, was carried out according to recommendations (longitudinal imaging on that portion $2 \mathrm{~cm}$ below the carotid bifurcation). Arterial stiffness is quantified by measurement of the speed of travel of the carotid pulse wave. This is measured by an echotracking system coupled with ultrasound equipment (e.TRACKING, Aloka, Japan), allowing, after B-mode scanning, simultaneous measurement of diameter variations and local speed at the common carotid. A validated algorithm is used to calculate the local carotid pulse wave velocity, which is directly proportional to carotid wall stiffness (25). PWV is expressed in meters per second $(\mathrm{m} / \mathrm{s})$

\section{Statistical analysis}

Firstly, a descriptive analysis was done on the data from the 3 groups of patients (MetS-, MetS+, and T2D). The distribution of categorical variables is shown in terms of numbers of individuals and percentages. Concerning quantitative variables showing asymmetrical distribution, the logarithmic transformation was used. Comparisons of the 3 groups were made using a Chi-square Test for the qualitative and quantitative variables, with a Fisher Test for overall comparison of means based on an analysis of variance (without adjustment)/ 
Citation: Gauthier A, Dubois S, Bertrais S, Gallois Y, Aube C, et al. (2012) The Leptin to Adiponectin Ratio is a Marker of the Number of Metabolic Syndrome Criteria in French Adults. J Metabolic Synd 1:101. doi:10.4172/2167-0943.1000101

Page 3 of 6

covariance (with adjustment for age and/or gender). If the overall difference was significant, the Bonferroni method was applied during mean comparison in order to take account of the multitude of tests. Relationships of leptin, adiponectin, and the leptin/adiponectin ratio to each insulin-resistance syndrome parameter were studied by determining unadjusted Spearman correlation coefficients, and then adjusting for gender and age. Mean comparisons among patients classified according to the number of MetS components were carried out using the Non-parametric Kruskal-Wallis Test. All analysis were done with SAS $^{\circledR}$ version 9.2 software (SAS Inc., Cary, NC). A 5\% significance level was set, and all tests are bilateral.

\section{Results}

\section{Comparison of the three groups}

The characteristics of the study population, depending on group, are shown in Table 1. The study includes 313 patients, of whom 122 present a metabolic syndrome without diabetes (MetS+), 94 are diabetic (T2D), and 97 have neither metabolic syndrome nor diabetes (MetS-). The 3 groups are comparable in terms of gender and smoking. MRI data are available for 161 patients and reveals higher visceral fat levels for T2D and MetS+ patients than for MetS- participants. The MetS+ group has a greater average weight and BMI than the T2D group, but the difference is not significant. Waist circumference and WHR are comparable regarding T2D and MetS+ participants. Percentage of visceral fat is significantly greater in T2D patients than in MetS+ patients. It is noteworthy that, for comparable BMI's, the amount of subcutaneous adipose tissue is greater in MetS+ patients than in T2D patients, although the difference does not reach statistically-significant levels.

The diabetics and MS patients show greater insulin resistance and have higher insulin and HOMA-IR levels than the MetS- group. Insulinemia is higher in MetS+ patients than in the T2D group, arguing for relative insulinopenia, which characterizes Type 2 diabetes. However, HOMA-IR values show a rise in diabetic patients, due to hyperglycemia. 10-year cardiovascular risk (Framingham-Laurier score) is higher among the T2D than the MetS+ and MetS- patients.

Data on adipokine values are given in Table 2. After adjustment for age and gender, leptin concentrations are significantly higher among only the MetS+ participants, which supports the observation that type 2 diabetics have less subcutaneous fat than MetS+, and therefore lower leptin concentrations as well. There is no significant difference among the adiponectin concentrations of our 3 groups, although there is a linear trend downward, from MetS- to MetS+, to T2D. However, the leptin to adiponectin ratio (L/A) is higher among the MetS+ and the T2D patients than the MetS-. Although statistically insignificant, the ratio is higher among the MetS+ than the T2D patients because of lower leptinemia among the T2D.

\section{Correlation between $\mathrm{L} / \mathrm{A}$ ratio and metabolic syndrome criteria}

Table 3 shows the associations between the L/A ratio and the

\begin{tabular}{|c|c|c|c|c|c|c|}
\hline & $\mathrm{N}$ & MetS - $(n=97)$ & MetS + $(n=122)$ & Diabétiques $(n=94)$ & P global & \\
\hline Men : n (\%) & - & $74(76.5 \%)$ & $94(77 \%)$ & $74(78.7 \%)$ & 0.69 & - \\
\hline Smoker : n (\%) & - & $22(22.6 \%)$ & $26(21.3 \%)$ & $11(11.7 \%)$ & 0.14 & - \\
\hline Age (years) & 313 & $51.3 \pm 10.0$ & $54.2 \pm 9.4$ & $57.9 \pm 8.5$ & $<0.0001$ & $b, c$ \\
\hline Weight (kg) & 313 & $80.4 \pm 13.2$ & $93.3 \pm 16.4$ & $91.3 \pm 12.5$ & $<0.0001$ & $a, b$ \\
\hline Height (m) & 313 & $1.68 \pm 0.09$ & $1.68 \pm 0.08$ & $1.68 \pm 0.10$ & 0.97 & - \\
\hline $\mathrm{BMI}\left(\mathrm{kg} / \mathrm{m}^{2}\right)$ & 313 & $28.4 \pm 4.7$ & $32.9 \pm 5.2$ & $32.5 \pm 4.5$ & $<0.0001$ & $a, b$ \\
\hline Waist circumference $(\mathrm{cm})$ & 313 & $96.1 \pm 11.0$ & $108.9 \pm 12.4$ & $108.6 \pm 10.4$ & $<0.0001$ & $a, b$ \\
\hline Hips (cm) & 313 & $102.4 \pm 9.3$ & $110.4 \pm 10.6$ & $109.5 \pm 10.0$ & $<0.0001$ & $a, b$ \\
\hline WHR & 313 & $0.94 \pm 0.07$ & $0.99 \pm 0.07$ & $0.99 \pm 0.07$ & $<0.0001$ & $a, b$ \\
\hline VAT $\left(\mathrm{cm}^{2}\right)$ & 161 & $132.5 \pm 72.4$ & $207.4 \pm 90.2$ & $222.3 \pm 90.0$ & $<0.0001$ & $a, b$ \\
\hline $\mathrm{SAT}\left(\mathrm{cm}^{2}\right)$ & 161 & $203.0 \pm 87.4$ & $269.0 \pm 125$ & $234.3 \pm 142.0$ & 0.0117 & a \\
\hline VAT $(\%)$ & 161 & $38.5 \pm 16.7$ & $44.3 \pm 15.6$ & $49.1 \pm 16.9$ & 0.0092 & b \\
\hline Systolic BP (mmHg) & 313 & $124.2 \pm 12.7$ & $132.0 \pm 13.4$ & $131.1 \pm 13.4$ & $<0.0001$ & $a, b$ \\
\hline Diastolic BP (mmHg) & 313 & $75.7 \pm 9.0$ & $79.2 \pm 9.6$ & $77.9 \pm 9.7$ & 0.0177 & a \\
\hline Pulse pressure $(\mathrm{mmHg})$ & 313 & $48.5 \pm 9.9$ & $52.7 \pm 10.0$ & $53.2 \pm 9.9$ & 0.0008 & $a, b$ \\
\hline Heart rate (beats./min) & 313 & $66.6 \pm 10.7$ & $69.2 \pm 10.6$ & $71.9 \pm 11.4$ & 0.0024 & $b$ \\
\hline $\mathrm{HbA} 1 \mathrm{c}(\%)$ & 313 & $5.65 \pm 0.34$ & $5.83 \pm 0.46$ & $6.80 \pm 0.68$ & $<0.0001$ & $a, b, c$ \\
\hline Glucose (g/l) & 313 & $0.95 \pm 0.11$ & $1.09 \pm 0.13$ & $1.34 \pm 0.25$ & $<0.0001$ & $a, b, c$ \\
\hline Insulin $(\mathrm{mU} / \mathrm{l})^{+}$ & 313 & $9.6 \pm 0.51$ & $17.5 \pm 0.89$ & $16.9 \pm 0.94$ & $<0.0001$ & $a, b$ \\
\hline $\mathrm{HOMA}-\mathrm{IR}^{*}$ & 313 & $2.19 \pm 0.21$ & $4.60 \pm 0.24$ & $5.43 \pm 0.41$ & $<0.0001$ & $a, b$ \\
\hline Total cholesterol (g/l) & 313 & $2.15 \pm 0.44$ & $2.04 \pm 0.42$ & $1.83 \pm 0.43$ & $<0.0001$ & $b, c$ \\
\hline HDL cholesterol (g/l) & 313 & $0.65 \pm 0.18$ & $0.57 \pm 0.18$ & $0.54 \pm 0.14$ & $<0.0001$ & $a, b$ \\
\hline LDL cholesterol (g/l) & 313 & $1.26 \pm 0.39$ & $1.14 \pm 0.37$ & $0.99 \pm 0.38$ & $<0.0001$ & $a, b, c$ \\
\hline Triglycerides $(\mathrm{g} / \mathrm{l})^{*}$ & 313 & $1.08 \pm 0.05$ & $1.61 \pm 0.07$ & $1.37 \pm 0.06$ & $<0.0001$ & $a, b, c$ \\
\hline $\begin{array}{l}\text { Framingham-Laurier } \\
10 \text {-year cardiovascular risk }\end{array}$ & 313 & $2.77 \pm 2.48$ & $4.34 \pm 3.03$ & $6.74 \pm 4.13$ & $<0.0001$ & $a, b, c$ \\
\hline
\end{tabular}

*asymmetrical distribution of values. Statistical tests were carried out on the logarithmic transform; reported values are geometric means and their confidence interval is $95 \%$.

a : $p<0.05$ for the difference between MetS- and MetS+ by the Bonferroni t-test

$b$ : $p<0.05$ for the difference between MetS- and Diabetics by the Bonferroni t-test

$c: p<0.05$ for the difference between MetS- and Diabetics by the Bonferroni t-test

BMI : Body Mass Index, WHR : Waist-to-Hip Ratio, VAT : Visceral Adipose Tissue, SAT : Subcutaneous Adipose Tissue, HbA1c : glycosylated hemoglobin, HOMA-IR : Homeostasis Model Assessment Insulin-Resistance 
Citation: Gauthier A, Dubois S, Bertrais S, Gallois Y, Aube C, et al. (2012) The Leptin to Adiponectin Ratio is a Marker of the Number of Metabolic Syndrome Criteria in French Adults. J Metabolic Synd 1:101. doi:10.4172/2167-0943.1000101

Page 4 of 6

\begin{tabular}{|c|c|c|c|c|c|c|}
\hline & $\mathrm{N}$ & $\begin{array}{l}\text { MetS - } \\
(\mathrm{n}=97)\end{array}$ & $\begin{array}{l}\text { MetS + } \\
(n=122)\end{array}$ & $\begin{array}{l}\text { Diabetics } \\
(n=94)\end{array}$ & $\begin{array}{l}P \\
\text { global }\end{array}$ & \\
\hline Men : n (\%) & 313 & $68(70.1 \%)$ & $88(72.1 \%)$ & $71(75.5 \%)$ & 0.70 & - \\
\hline Age (years) & 313 & $51.4 \pm 10.0$ & $54.2 \pm 9.3$ & $58.1 \pm 8.6$ & $<0.0001$ & $b, c$ \\
\hline \multicolumn{7}{|l|}{ Leptin $(\mu \mathbf{g} / \mathrm{l})^{*}$} \\
\hline unadjusted & 313 & $\begin{array}{l}9.67 \\
{[8.14-11.49]}\end{array}$ & \begin{tabular}{|l|}
17.75 \\
{$[15.22-20.70]$}
\end{tabular} & $\begin{array}{l}14.07 \\
{[11.81-16.76]}\end{array}$ & $<0.0001$ & $a, b$ \\
\hline adjusted for age & 313 & $\begin{array}{l}10.19 \\
{[8.58-12.11]}\end{array}$ & $\begin{array}{l}17.85 \\
{[15.34-20.77]}\end{array}$ & $\begin{array}{l}13.23 \\
{[11.09-15.78]}\end{array}$ & $<0.0001$ & $a, c$ \\
\hline adjusted for gender and age & 313 & $\begin{array}{l}9.84 \\
{[8.52-11.37]}\end{array}$ & $\begin{array}{l}17.76 \\
{[15.65-20.14]}\end{array}$ & $\begin{array}{l}13.81 \\
{[11.92-16.00]}\end{array}$ & $<0.0001$ & $a, b, c$ \\
\hline \multicolumn{7}{|l|}{ Adiponectin (mg/l) } \\
\hline$-\quad$ unadjusted $\dagger$ & 313 & $7.37 \pm 3.48$ & $7.24 \pm 3.37$ & $7.02 \pm 3.59$ & 0.78 & - \\
\hline adjusted for age $\ddagger$ & 313 & $7.74 \pm 0.340$ & $7.28 \pm 0.298$ & $6.60 \pm 0.347$ & 0.07 & - \\
\hline adjusted for gender and age $\ddagger$ & 313 & $7.69 \pm 0.332$ & $7.28 \pm 0.291$ & $6.66 \pm 0.340$ & 0.10 & - \\
\hline \multicolumn{7}{|l|}{ Leptine/Adiponectin Ratio* } \\
\hline unadjusted & 313 & $\begin{array}{l}1.45 \\
{[1.21-1.75]}\end{array}$ & $\begin{array}{l}2.73 \\
{[2.31-3.22]}\end{array}$ & $\begin{array}{l}2.27 \\
{[1.88-2.74]}\end{array}$ & $<0.0001$ & $a, b$ \\
\hline adjusted for age & 313 & $\begin{array}{l}1.46 \\
{[1.21-1.76]}\end{array}$ & $\begin{array}{l}2.73 \\
{[2.31-3.22]}\end{array}$ & $\begin{array}{l}2.26 \\
{[1.86-2.74]}\end{array}$ & $<0.0001$ & $a, b$ \\
\hline Adjusted for gender and age & 313 & $\begin{array}{l}1.42 \\
{[1.19-1.69]}\end{array}$ & $\begin{array}{l}2.72 \\
{[2.33-3.16]}\end{array}$ & $\begin{array}{l}2.34 \\
{[1.96-2.80]}\end{array}$ & $<0.0001$ & $a, b$ \\
\hline
\end{tabular}

*asymmetrical distribution of values. Statistical tests were carried out on the logarithmic transform; reported values are geometric means and their confidence interval is $95 \%$.

$\dagger$ mean \pm standard deviation

$\ddagger$ mean \pm standard error (or standard error of the mean $=$ standard deviation $/ \sqrt{n}$ )

a : $p<0.05$ for the difference between MetS- and MetS+ by the Bonferroni t-test

$b: p<0.05$ for the difference between MetS- and Diabetics by the Bonferroni t-test

$c: p<0.05$ for the difference between Met+ and Diabetics by the Bonferroni t-test

Table 2: Comparison of raw and adjusted (for age and gender) adiponectin and leptin concentrations and ratios among the 3 groups.

clinical and laboratory criteria of metabolic syndrome. There is a significant correlation between the L/A ratio and each of the criteria for metabolic syndrome: waist circumference $(\mathrm{r}=0.56)$; systolic arterial blood pressure $(\mathrm{r}=0.17)$; diastolic arterial blood pressure $(\mathrm{r}=0.11)$; triglycerides $(r=0.24)$; HDL cholesterol $(r=0.27)$; glycemia $(r=0.126)$. The L/A ratio is also significantly correlated with WHR, although less so than with waist circumference alone. Additionally, there is a strong association between the amount of visceral fat and the L/A ratio $(\mathrm{r}=0.51)$. It is positively and strongly correlated with HOMA-IR $(r=0.59)$. Surprisingly, LDL cholesterol is negatively linked to the L/A ratio.

\section{$\mathrm{L} / \mathrm{A}$ ratio and the number of metabolic syndrome criteria}

Figure 1 shows the relation between the L/A ratio figure (transformed into Log) and the number of metabolic syndrome components. The L/A ratio is positively linked to the number of metabolic syndrome components $(\mathrm{r}=0.35)$. The greater the number of criteria a patient presented, the higher the L/A ratio for that patient. Among patients presenting no MetS criteria, the L/A ratio is on average close to 1 (0.989). Patients showing all metabolic syndrome criteria have a mean ratio of 6.148 . The mean of L/A ratios for one, two, three, and four criteria are, respectively, 1.567, 2.743, 3.166, and 4.060. Among non-diabetics in the study (results not shown here), the relation between the metabolic syndrome criteria and the L/A ratio is the same as that found in the whole population, indicating that diabetic status does not influence that relation.

\section{Correlation with cardiovascular parameters}

Table 4 shows the correlations between the L/A ratio and cardiovascular parameters. The L/A ratio is positively correlated with minimum carotid diameter but is not associated with intima-media thickness. Aortic PWV is significantly and positively associated with the $\mathrm{L} / \mathrm{A}$ ratio $(\mathrm{p}<0.0001)$.

\section{Discussion}

Metabolic syndrome is a frequently-encountered condition associating insulin resistance, android weight distribution, glucose and lipid profile anomalies, and hypertension, thereby increasing cardiovascular risk. Several studies have found a link between adiponectin, leptin, and metabolic syndrome in various populations $[26,27]$. In the present study, we show that the leptin/adiponectin ratio is a marker of all metabolic syndrome criteria. This ratio is positively linked to, and increases with, the number of metabolic syndrome criteria, independent of age, gender, or the presence of diabetes.

In our study, we confirm that the concentrations of leptin is higher in patients with metabolic syndrome than in those without it. Adiponectin concentrations are lower in patients with metabolic syndrome than in those without it, though the difference is not significant. On the other hand, the leptin/adiponectin ratio is significantly higher among metabolic syndrome patients. As in Zhuo's study, based on a Chinese population of more than 2000 plus-60-year-olds, we observed that the $\mathrm{L} / \mathrm{A}$ ratio is associated with each metabolic syndrome component [18]. While our population is smaller, it includes both genders and all age groups, from 18 to 75 years of age. Our data show a significant link between the L/A ratio and the number of metabolic syndrome components, even after adjustment for age and gender. Moreover, we find that the link is even stronger as the number of criteria increases. The ratio is about 7 times greater if all criteria of metabolic syndrome are present. The ratio remains positively linked to metabolic syndrome criteria after exclusion of diabetics. Mojiminiyi et al. [19] showed that the $\mathrm{L} / \mathrm{A}$ ratio is not the best marker of metabolic syndrome, discovering a stronger link with adiponectin [19]. However, that population was smaller, and all participants were diabetics.

We find that the leptin/adiponectin ratio is positively linked to 


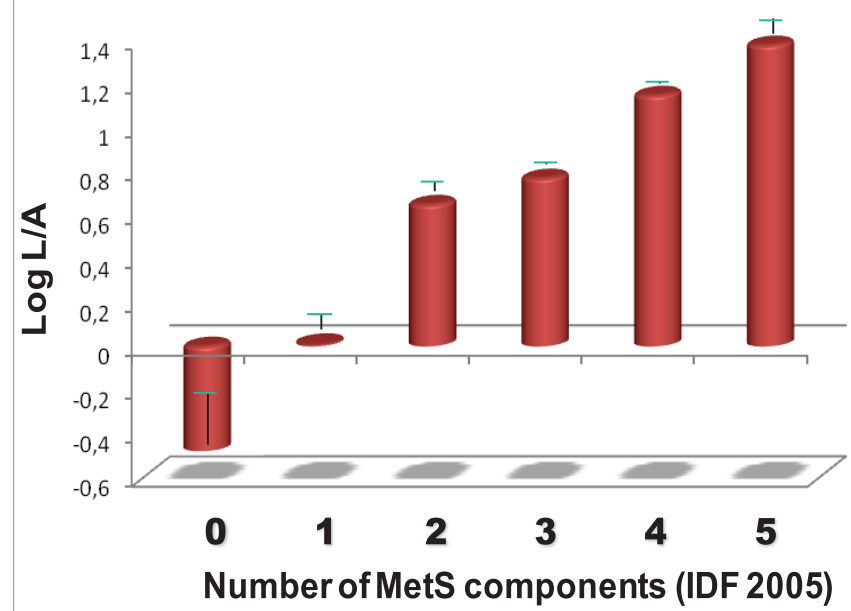

Figure 1: Relation between the L/A Ratio and metabolic syndrome criteria. The Non-Parametric Kruskal-Wallis Test $(p<0.0001)$. Spearman Correlation Coefficient : $(r=0.356, p<0.001)$

\begin{tabular}{|l|l|l|}
\hline & $\mathrm{r}$ & $\mathrm{p}$ value \\
\hline BMI $\left(\mathrm{kg} / \mathrm{m}^{2}\right)$ & 0.568 & $<0.0001$ \\
\hline Waist Circumference $(\mathrm{cm})$ & 0.567 & $<0.0001$ \\
\hline WHR & 0.274 & $<0.0001$ \\
\hline Systolic blood pressure $(\mathrm{mmHg})$ & 0.172 & 0.0023 \\
\hline Diastolic blood pressure $(\mathrm{mmHg})$ & 0.116 & 0.0408 \\
\hline Log Triglycerides $(\mathrm{g} / \mathrm{l})$ & 0.239 & $<0.0001$ \\
\hline HDL cholesterol $(\mathrm{g} / \mathrm{l})$ & -0.274 & $<0.0001$ \\
\hline LDL cholesterol $(\mathrm{g} / \mathrm{l})$ & -0.121 & 0.0332 \\
\hline Glycemia $(\mathrm{g} / \mathrm{l})$ & 0.126 & 0.0255 \\
\hline HbA1c $(\%)$ & 0.110 & 0.0531 \\
\hline Log HOMA-I & 0.592 & $<0.0001$ \\
\hline Visceral Adipose Tissue $\left(\mathrm{cm}^{2}\right)$ & 0.518 & $<0.0001$ \\
\hline Visceral Adipose Tissue $(\%)$ & 0.246 & 0.0025 \\
\hline
\end{tabular}

BMI: Body Mass Index; WHR: Waist-to-hip Ratio; HOMA-IR: Homeostasis Model Assessment Insulin-Resistance

Table 3: Spearman Correlation Coefficients for the leptin/adiponectin (L/A) Ratio adjusted for gender and age, with metabolic syndrome parameters.

\begin{tabular}{|l|l|l|}
\hline & $r$ & $p$ value \\
\hline Mean minimum carotid diameter $(\mathrm{mm})$ & 0.153 & 0.0111 \\
\hline Mean IMT $(\mathrm{mm})$ & -0.069 & 0.2410 \\
\hline Mean carotid PWV $(\mathrm{m} / \mathrm{s})$ & 0.255 & $<0.0001$ \\
\hline
\end{tabular}

PWV: pulse wave velocity; IMT: intima media thickness

Table 4: Spearman Correlation Coefficients for L/A, adjusted for gender and age, and vascular parameters.

glycemia and the log HOMA-IR, which is in line with data from studies finding an association between the ratio and insulin resistance [28,29]. In our study, anthropometric criteria and the insulin-resistance marker show the strongest links to the L/A ratio. Our data show that BMI and the Waist-to-hip Ratio are positively linked to the L/A ratio, which is in harmony with several studies including that of Karakas [30]. In addition, it is shown that leptin and adiponectin are positively and negatively linked, respectively, to visceral fat [11]. Our study demonstrates that the L/A ratio is also strongly linked to visceral fat as measured by MRI. In our study population, we find that Type 2 diabetics have less subcutaneous fat and lower hip circumference measurements than the MetS+ patients, even if the difference is not significant. Some studies have suggested a protective role for subcutaneous fat. Kim et al. [31], for example, found a negative correlation between subcutaneous fat and metabolic syndrome [31]. In Kumagai's study, the amount of subcutaneous fat is negatively correlated with the leptin/adiponectin ratio [32].

PWV is a marker of vascular stiffness, reflecting arterial noncompliance, and is therefore linked to a risk of cardiovascular events. In addition, aortic PWV is found to be correlated with the Framingham score [22]. Some studies have demonstrated a link between PWV and metabolic syndrome [23,33]. Nakanishi has shown that aortic PWV increases along with the number of metabolic syndrome criteria [34]. In that study, cardiovascular risk factors that most strongly linked to an increase in PWV were hypertension, hypercholesterolemia, obesity, and hyperuricemia. Conversely, high PWV seemed to be an independent predictor of the presence of metabolic syndrome [23]. PWV increases with age and male gender; here we note a positive link between carotid PWV and the leptin/adiponectin ratio, after adjustment for age and gender. We therefore confirm the data of Satoh et al., finding an association between the L/A ratio and PWV which is stronger than that observed with leptin or adiponectin alone [35].

There are some limitations of our study. Several confounding factors were not taken into account here, such as exercise, diet, alcohol consumption, and medication. The aim of the study was to select a population that was best representative of at-risk cardiovascular patients. Taking antidiabetic or antihypertensive medications is in itself one of the criteria of the definition of metabolic syndrome used here (IDF, 2005). Most patients at risk of cardiovascular events are already taking such medication. The purpose here was to study a group of patients that was as representative as possible of those metabolic syndrome patients receiving adequate care. This was an observational study and we cannot reach conclusions regarding cause and effect. We find no significant difference in adiponectin concentrations among the 3 groups, despite a linear trend downward. Adiponectin is in fact found in 3 isoforms whose active molecule may be the isoform with the highest molecular weight, 300kD (HMW: High Molecular Weight) [36]. It is suggested that this HMW isoform of adiponectin is a better biomarker of metabolic syndrome and of insulin resistance than total adiponectin and may therefore better predict the onset of metabolic syndrome [37].

In conclusion, our study shows a positive association between the leptin/adiponectin ratio and every one of the criteria of metabolic syndrome, independently of gender, age, or the presence of diabetes. This ratio is also linked to the amount of visceral fat, as estimated by MRI. The L/A ratio increases in value along with the number of criteria of metabolic syndrome.

\section{Acknowledgements}

We wish to thank all those volunteers who participated in the study. We also wish to thank the primary-care teams in the selected areas, as well as Catherine Bertrand and Nadine Belloeil. The study was supported by a donation from the Lilly France Laboratories for adipokine measurements.

\section{References}

1. Alberti KG, Zimmet PZ (1998) Definition, diagnosis and classification of diabetes mellitus and its complications. Part 1: diagnosis and classification of diabetes mellitus provisional report of a WHO consultation. Diabet Med 15: 539-553.

2. Benetos A, Thomas F, Pannier B, Bean K, Jégo B, et ai. (2008) All-cause and cardiovascular mortality using the different definitions of metabolic syndrome. Am J Cardiol 102: 188-191.

3. Ford ES (2005) Prevalence of the metabolic syndrome defined by the International Diabetes Federation among adults in the U.S. Diabetes Care 28 2745-2749. 
4. Julia C, Vernay M, Salanave B, Deschamps V, Malon A, et al. (2010) Nutrition patterns and metabolic syndrome: a need for action in young adults (French Nutrition and Health Survey - ENNS, 2006-2007). Prev Med 51: 488-493.

5. Lapidus L, Bengtsson C, Larsson B, Pennert K, Rybo E, et al. (1984) Distribution of adipose tissue and risk of cardiovascular disease and death: a 12 year follow up of participants in the population study of women in Gothenburg. Sweden. Br Med J (Clin Res Ed) 289: 1257-1261.

6. Matsuzawa Y, Funahashi T, Nakamura T (1999) Molecular mechanism of metabolic syndrome $\mathrm{X}$ : contribution of adipocytokines adipocyte-derived bioactive substances. Ann N Y Acad Sci 892: 146-154.

7. Agata J, Masuda A, Takada M, Higashiura K, Murakami H, et al. (1997) High plasma immunoreactive leptin concentrations in essential hypertension. Am J Hypertens 10: 1171-1174.

8. Wallace AM, McMahon AD, Packard CJ, Kelly A, Shepherd J, et al. (2001) Plasma leptin and the risk of cardiovascular disease in the west of Scotland coronary prevention study (WOSCOPS). Circulation 104: 3052-3056.

9. Söderberg S, Ahrén B, Stegmayr B, Johnson O, Wiklund PG, et al. (1999) Leptin is a risk marker for first-ever hemorrhagic stroke in a population-based cohort. Stroke 30: 328-337.

10. Yamauchi T, Kamon J, Minokoshi Y, Ito Y, Waki H, et al. (2002) Adiponectin stimulates glucose utilization and fatty-acid oxidation by activating AMPactivated protein kinase. Nat Med 8: 1288-1295.

11. Staiger H, Tschritter O, Machann J, Thamer C, Fritsche A, et al. (2003) Relationship of serum adiponectin and leptin concentrations with body fat distribution in humans. Obes Res 11: 368-372.

12. Matsubara M, Maruoka S, Katayose S (2002) Inverse relationship between plasma adiponectin and leptin concentrations in normal-weight and obese women. Eur J Endocrinol 147: 173-180.

13. Matsubara M, Katayose S, Maruoka S (2003) Decreased plasma adiponectin concentrations in nondiabetic women with elevated homeostasis model assessment ratios. Eur J Endocrinol 148: 343-350.

14. Kazumi T, Kawaguchi A, Sakai K, Hirano T, Yoshino G (2002) Young men with high-normal blood pressure have lower serum adiponectin, smaller LDL size, and higher elevated heart rate than those with optimal blood pressure. Diabetes Care 25: 971-976.

15. Matsubara M, Maruoka S, Katayose S (2002) Decreased plasma adiponectin concentrations in women with dyslipidemia. J Clin Endocrinol Metab 87: 2764 2769 .

16. Kojima S, Funahashi T, Maruyoshi H, Honda O, Sugiyama S, et al. (2005) Concentrations of the adipocyte-derived plasma protein, adiponectin, have a close relationship with atheroma. Thromb Res 115: 483-490.

17. Thorand B, Zierer A, Baumert J, Meisinger C, Herder C, et al. (2010) Associations between leptin and the leptin / adiponectin ratio and incident Type 2 diabetes in middle-aged men and women: results from the MONICA / KORA Augsburg study 1984-2002. Diabet Med 27: 1004-1011.

18. Zhuo Q, Wang Z, Fu P, Piao J, Tian Y, et al. (2009) Comparison of adiponectin leptin and leptin to adiponectin ratio as diagnostic marker for metabolic syndrome in older adults of Chinese major cities. Diabetes Res Clin Pract 84 27-33.

19. Mojiminiyi OA, Abdella NA, Al Arouj M, Ben Nakhi A (2007) Adiponectin, insulin resistance and clinical expression of the metabolic syndrome in patients with Type 2 diabetes. Int J Obes (Lond) 31: 213-220.

20. Kotani K, Sakane N, Saiga K, Kurozawa Y (2005) Leptin to adiponectin ratio as an atherosclerotic index in patients with type 2 diabetes: relationship of the index to carotid intima-media thickness. Diabetologia 48: 2684-2686.

21. Norata GD, Raselli S, Grigore L, Garlaschelli K, Dozio E, et al. (2007) Leptin:adiponectin ratio is an independent predictor of intima media thickness of the common carotid artery. Stroke 38: 2844-2846.

22. Blacher J, Asmar R, Djane S, London GM, Safar ME (1999) Aortic pulse wave velocity as a marker of cardiovascular risk in hypertensive patients. Hypertension 33: 1111-1117.

23. Achimastos AD, Efstathiou SP, Christoforatos T, Panagiotou TN, Stergiou GS et al. (2007) Arterial stiffness: determinants and relationship to the metabolic syndrome. Angiology 58: 11-20.

24. Ducluzeau PH, Manchec-Poilblanc P, Roullier V, Cesbron E, Lebigot J, et al. (2010) Distribution of abdominal adipose tissue as a predictor of hepatic steatosis assessed by MRI. Clin Radiol 65: 695-700.
25. Harada A, Okada T, Niki K, Chang D, Sugawara M (2002) On-line noninvasive one-point measurements of pulse wave velocity. Heart Vessels 17: 61-68.

26. Ryo M, Nakamura T, Kihara S, Kumada M, Shibazaki S, et al. (2004) Adiponectin as a biomarker of the metabolic syndrome. Circ J 68: 975-981.

27. Lee JM, Kim SR, Yoo SJ, Hong OK, Son HS, et al. (2009) The relationship between adipokines, metabolic parameters and insulin resistance in patients with metabolic syndrome and type 2 diabetes. J Int Med Res 37: 1803-1812.

28. Oda N, Imamura S, Fujita T, Uchida Y, Inagaki K, et al. (2008) The ratio of leptin to adiponectin can be used as an index of insulin resistance. Metabolism 57: $268-273$

29. Funicane FM, Luan J, Wareham NJ, Sharp SJ, O'Rahilly S, et al. (2009) Correlation of the leptin:adiponectin ratio with measures of insulin resistance in non-diabetic individuals. Diabetologia 52: 2345-2349.

30. Karakas M, Zierer A, Herder C, Baumert J, Meisinger C, et al. (2010) Leptin, adiponectin, their ratio and risk of Coronary Heart Disease: results from the MONICA/KORA Augsburg Study 1984-2002. Atherosclerosis 209: 220-225.

31. Kim S, Cho B, Lee H, Choi K, Hwang SS, et al. (2011) Distribution of Abdomina Visceral and Subcutaneous Adipose Tissue and Metabolic Syndrome in a Korean Population. Diabetes Care 34: 504-506.

32. Kumagai S, Kishimoto H, Masatakasuwa, Zou B, Harukasasaki (2005) The leptin to adiponectin ratio is a good biomarker for the prevalence of metabolic syndrome, dependent on visceral fat accumulation and endurance fitness in obese patients with diabetes mellitus. Metab Syndr Relat Disord 3: 85-94.

33. Roes SD, Alizadeh Dehnavi R, Westenberg JJM, Lamb HJ, Mertens BJA et al. (2008) Assessment of aortic pulse wave velocity and cardiac diastolic function in subjects with and without the metabolic syndrome: HDL cholestero is independently associated with cardiovascular function. Diabetes Care. 31: $1442-1444$.

34. Nakanishi N, Suzuki K, Tatara K (2003) Clustered features of the metabolic syndrome and the risk for increased aortic pulse wave velocity in middle-aged Japanese men. Angiology 54: 551-559.

35. Satoh N, Naruse M, Usui T, Tagami T, Suganami T, et al. (2004) Leptin-toadiponectin ratio as a potential atherogenic index in obese type 2 diabetic patients. Diabetes Care 27: 2488-2490.

36. Pajvani UB, Hawkins M, Combs TP, Rajala MW, Doebber T, et al. (2004) Complex distribution, not absolute amount of adiponectin, correlates with thiazolidinedione-mediated improvement in insulin sensitivity. J Biol Chem 279 12152-12162.

37. Seino Y, Hirose H, Saito I, Itoh H (2009) High-molecular-weight adiponectin is a predictor of progression to metabolic syndrome: a population-based 6-year follow-up study in Japanese men. Metab Clin Exp 58: 355-360. 